\title{
Numerical Simulation of Parallel Cutting with Different Number of Empty Holes
}

\author{
Xiantang ZHANG*, Juan LI, Dan LI, Shizhen XIE, Hongmin ZHOU, Tingchun LI
}

\begin{abstract}
The cutting blasting plays a key role in rock excavation construction, which determines the blasting effect and efficiency of the entire blasting project. In the cutting blasting, parallel holes are often used as the auxiliary free surface and the compensation space of blasting rock, and the empty holes have a great influence on the blasting effect. In this paper, Ansys/Ls-Dyna finite element analysis software is carried out to simulate four models with different number of empty holes. The simulation results show that the stronger the guiding effect of the empty holes on the crack propagation, the more obvious the inhibition effect on the crack in the remaining direction. The initial crack near the empty hole is generated by the continuous action of the stress wave, and the empty hole promotes the propagation of the explosion stress wave. The inconsistent guiding directions of adjacent empty holes are one of the reasons for the unsatisfactory blasting effect of multiple small diameter empty holes. The closer the empty hole is to the blasthole, the larger the maximum principal stress. By comparing the results of calculation with the numerical simulation, it is verified that the maximum principal stress near the empty hole is similar and the change rule is consistent. The above research has reference meaning to the location of the hollow hole in the actual blasting construction and the density of the empty hole.
\end{abstract}

Keywords: action mechanism of empty hole; numerical simulation; parallel cut; rock fragmentation process; stress concentration

\section{INTRODUCTION}

The empty hole can provide auxiliary free surface and the compensation space of rock breaking process for blasting. Theoretically, it is possible to increase the blasting effect by appropriately increasing the volume of empty holes, but the diameter of the empty hole and the diameter of the blasthole are the same in some conditions under the actual blasting construction. In this case, there may be multiple small diameter blastholes due to the equipment error and the quality of the operator will cause the blasting effect to be unsatisfactory or even fail. This paper explores the reason for the other side, the influence of the guiding effect of adjacent holes on the blasting effect when the multi-holes are arranged.

Numerical simulation makes up for the limitation of the field test and the complexity of theoretical calculation, and it becomes a new method to study rock blasting failure mechanism and predicting blasting result. Li Qiyue [1] established a theoretical model by ANSYS finite element analysis software, and obtained that the tensile failure and compression damage of rock under stress wave are more obvious with the increase of empty hole diameter. In Zhang Qi [2] by means of mechanical model and numerical calculation, the factors influencing the effect of cutting blasting are quantitatively analyzed, as well as the effect of empty holes in Parallel cutting. Lin Daneng [3] based on the typical blasthole layout with empty holes, theoretically obtained the stress concentration effect, and the stress concentration effect will increase with the increase of the aperture. Ren Xing [4] from the point of numerical simulation concluded that the stress wave will decay gradually with the increase of distance in the propagation process. Zhu Zheming [5] established the fracture failure criterion of brittle materials under compressive loading based on the collinear double crack model and the single crack model and the traditional crack fracture criterion. Yang Renshu [6] studied the variation of the crack propagation trajectory, the expansion velocity and the dynamic stress intensity factor of the crack tip under different empty holes diameters. In Zhu Z [7] by using linear equation of state and the major principal stress failure criterion, numerical models were established by using
AUTODYN code, and the effective mechanism of empty holes on crack propagation behavior was studied numerically. The results show the following: Empty holes have the arrest function on outgoing cracks, and the arrest function depends on the two holes spacing; the shorter the two holes spacing is, the stronger the arrest function is. Wang Y. [8] - combining the experimental and numerical results, it can be concluded that the influence of empty hole defects of brittle materials on dynamic fracturing is great. Yan Yaofeng [9] used numerical simulation to observe the stress cloud diagram and stress time history curve during the explosion process, and obtained the effect of empty holes effect on rock failure under the condition of empty holes.

There are many researches on the influence of the diameter of the empty hole on the blasting effect, and the research on the influence of the number of empty holes and the position of the empty hole on the blasting rock breaking effect is less.

\section{GEOMETRIC MODEL AND STATE PARAMETERS}

\subsection{Establishment of Geometric Models}

Design excavation section $12 \mathrm{~m}^{2}$ in a mining area in northern China, no inclination angle. Rock firmness coefficient $f=15$. The nature of the rock is solid granite. The density is $2.471 \mathrm{~g} / \mathrm{cm}^{3}$. The compressive strength of rock is $150 \mathrm{MPa}$, Poisson's ratio is 0.25 . The rock formation is stable and does not contain water, and has a simple geological structure. According to the field blasting experiment, the cutting model was established as four blast holes, which includes four models: Model I, four blast holes plus center empty hole diamond arrangement; Model II, four blast holes and two vertical empty holes in a diamond arrangement; Model III, four blast holes and three vertical empty holes in a diamond arrangement; Model IV, four blast holes and four vertical empty holes in a diamond arrangement.

The overall model size is $600 \times 600 \times 1 \mathrm{~cm}$, the blast hole diameter is $0.04 \mathrm{~m}, \mathrm{~A}, \mathrm{~B}, \mathrm{C}, \mathrm{D}$ blast holes are charging holes, E, F, G, H are empty holes, and the specific spacing and blast holes arrangement are shown in Fig. 1. (Unit: $\mathrm{mm})$. 


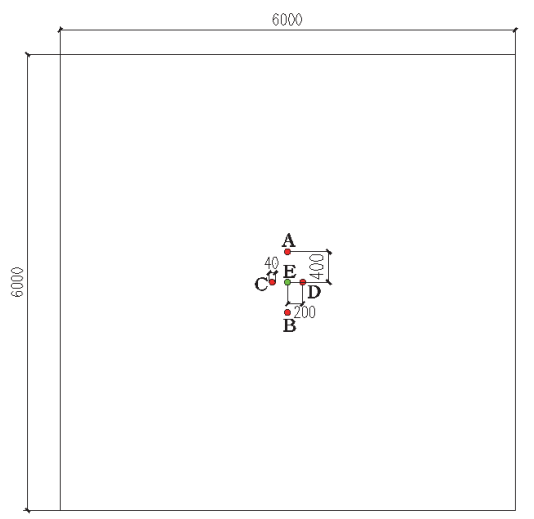

Model I
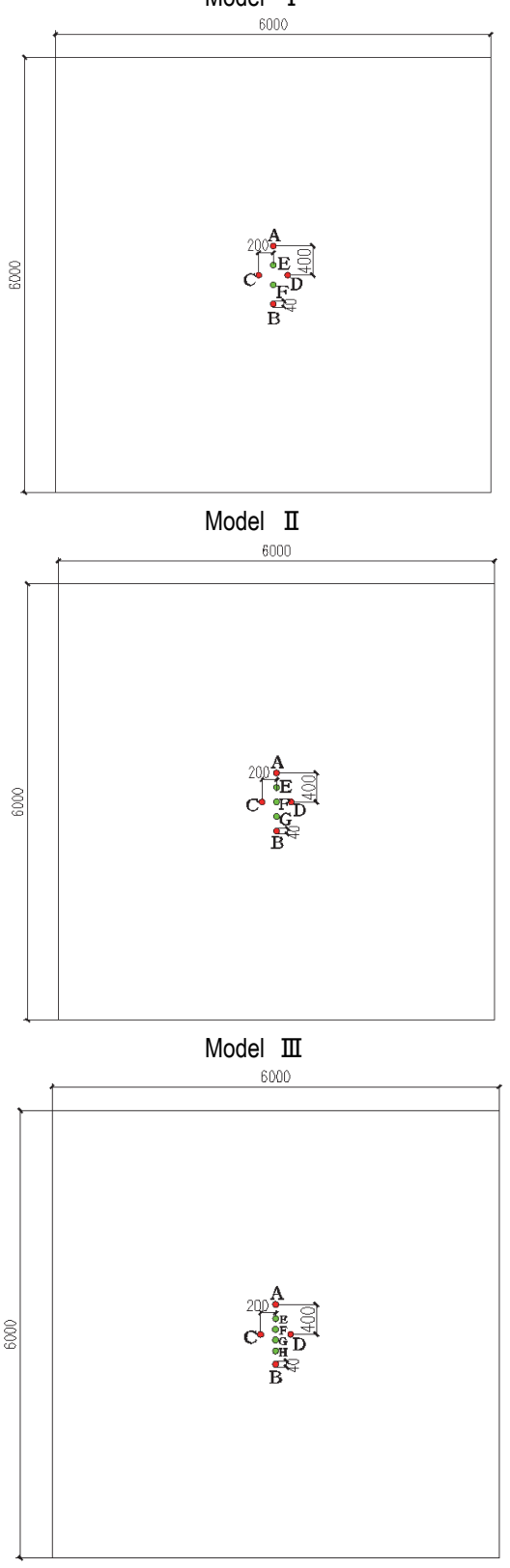

Model IV

Figure 1 Specific spacing and blast holes arrangement

\subsection{Material Parameters \\ 2.2.1 Unit Algorithm}

Model uses SOLID164 hexahedral solid element, coupled with charges; In order to prevent the reflection superposition of the explosive stress wave from affecting the calculation result, no reflection boundary condition is set around the model; Apply fixed constraints to the bottom of the model to prevent rigid body displacement; Simulation is simplified to a plane strain problem, calculated using a single layer grid; when calculating, all holes detonate at the same time. A Fluid-structure interaction algorithm is selected for the calculation model.

\subsubsection{Rock Model}

The constitutive model of rock media uses HJC constitutive equation to simulate the large deformation behavior and high strain rate characteristics of rock under explosion impact dynamic load, and the key word is *MAT JOHNSON HOLMQUIST CONCRETE.

By adding the failure criterion, the damage and failure of the unit are used to simulate the dynamic expansion of the rock crack and the formation process of the cavity. The specific rock material parameters are shown in Tab. 1 [10].

Table 1 Material parameters of HJC model of rock material

\begin{tabular}{|c|c|c|c|}
\hline Density $\rho / \mathrm{g} / \mathrm{cm}^{3}$ & 2.471 & $\begin{array}{c}\text { Pressure parameter } \\
K_{1} / \mathrm{GPa}\end{array}$ & 85 \\
\hline $\begin{array}{c}\text { Compressive strength } \\
f_{\mathrm{c}} / \mathrm{MPa}\end{array}$ & 150 & $\begin{array}{c}\text { Pressure parameter } \\
K_{2} / \mathrm{GPa} \\
\end{array}$ & 171 \\
\hline $\begin{array}{c}\text { Shear modulus } \\
G / \mathrm{GPa}\end{array}$ & 29.2 & $\begin{array}{c}\text { Pressure parameter } \\
K_{3} / \mathrm{GPa} \\
\end{array}$ & 208 \\
\hline $\begin{array}{c}\text { Tensile strength } \\
T / \mathrm{MPa}\end{array}$ & 6 & $P_{1} / \mathrm{GPa}$ & 1.00 \\
\hline $\begin{array}{c}\text { Crush volume pressure } \\
P_{\mathrm{C}} / \mathrm{MPa}\end{array}$ & 51 & $\begin{array}{c}\text { Compacted volume } \\
\text { pressure } U_{1} \\
\end{array}$ & 0.01 \\
\hline $\begin{array}{c}\text { Crush volume strain } \\
U_{\mathrm{C}} \\
\end{array}$ & 0.00278 & $\begin{array}{c}\text { Compacted volume } \\
\text { strain } A \\
\end{array}$ & 0.79 \\
\hline Poisson's ratio & 0.3 & $\begin{array}{c}\text { Cohesion strength } \\
B\end{array}$ & 1.60 \\
\hline $\begin{array}{l}\text { Maximum standard } \\
\text { strength } S F_{\max }\end{array}$ & 4 & $\begin{array}{c}\text { Strength parameter } \\
\qquad N\end{array}$ & 0.61 \\
\hline $\begin{array}{c}\text { Minimum plastic } \\
\text { strain change } E F_{\min }\end{array}$ & 0.005 & Failure type $f_{\mathrm{s}}$ & 0.004 \\
\hline
\end{tabular}

\subsubsection{Explosive Model}

The calculation model of explosive material is MAT_HIGH_EXPLOSIVE_BURN, and the EOS_JWL state equation is used to reflect the change of volume and pressure of detonation results after explosion, The JWL state equation is shown in Eq. (1):

$$
p=A\left(1-\frac{\omega}{R_{1}}\right) \mathrm{e}^{-R_{1} V}+B\left(1-\frac{\omega}{R_{2} V}\right) \mathrm{e}^{-R_{2} V}+\frac{\omega E_{0}}{V}
$$

where, $p$ is the pressure of the detonation product; $V$ is the relative volume of the detonation product; $E_{0}$ is the initial internal energy density of the detonation product; $A, B, R_{1}$, $R_{2}, \omega$ are material parameters.

Table 2 No. $11^{\text {th }}$ rock explosive parameters

\begin{tabular}{|l|c|c|}
\hline \multicolumn{1}{|c|}{ Density } & $\mathrm{kg} / \mathrm{m}^{3}$ & 1200 \\
\hline Explosion velocity & $\mathrm{GPa}$ & 4950 \\
\hline CJ pressure & $\mathrm{GPa}$ & 6.125 \\
\hline \multirow{4}{*}{$\begin{array}{l}\text { Parameter of JWL state } \\
\text { equation }\end{array}$} & $\mathrm{A} / \mathrm{GPa}$ & 52.4 \\
\cline { 2 - 3 } & $\mathrm{B} / \mathrm{GPa}$ & 0.768 \\
\cline { 2 - 3 } & $R_{1}$ & 4.2 \\
\cline { 2 - 3 } & $R_{2}$ & 1.1 \\
\cline { 2 - 3 } & $\omega$ & 0.34 \\
\cline { 2 - 3 } & $E / \mathrm{GPa}$ & 8.5 \\
\hline
\end{tabular}


In this paper, the number $11^{\text {th }}$ rock explosive is selected, and its parameters are shown in Tab. 2 [11-13].

Table 3 Parameters of air material parameters and State equations

\begin{tabular}{|c|c|}
\hline Density $/ \mathrm{g} / \mathrm{cm}^{3}$ & $1.29 \mathrm{E}-5$ \\
\hline$C_{0}$ & 0 \\
\hline$C_{1}$ & 0 \\
\hline$C_{2}$ & 0 \\
\hline$C_{3}$ & 0 \\
\hline$C_{4}$ & 0.4 \\
\hline$C_{5}$ & 0.4 \\
\hline$C_{6}$ & 0 \\
\hline$E / \mathrm{GPa}$ & 0.025 \\
\hline
\end{tabular}

\subsubsection{Air Model}

The air material model chooses the MAT_NULL air material model, its state equation is defined by the keyword EOS LINERAR POLYNOMIAL, and state equation is shown in Eq. (2):

$$
p=C_{0}+C_{1} \mu+C_{2} \mu^{2}+C_{3} \mu^{3}+\left(C_{4}+C_{5} \mu+C_{6} \mu^{2}\right) E
$$

where, $C_{i}$ is the equation parameter, $E$ is the unit initial internal energy of relative volume, $\mu=1 /(v-1), V$ is relative volume [14-16].

Specific air parameters are shown in Tab. 3.

\section{SIMULATION RESULTS ANALYSIS 3.1 Blasting Rock Breaking Process}

The mass of the remaining rock in the cavity is an important index to reflect the cutting effect at the end of the cutting blasting. The cutting is designed to provide compensating space and the free surface for rock fragmentation. At the end of the cutting blasting, the less large masses of rock in the cavity, the more obvious the effect of the cutting.

The blasting penetration process of a rock model containing different number of holes is shown in Fig. 2 [17, $18]$.

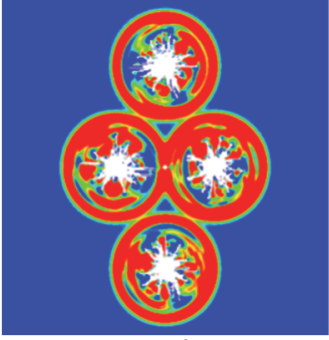

$50 \mu \mathrm{s}$

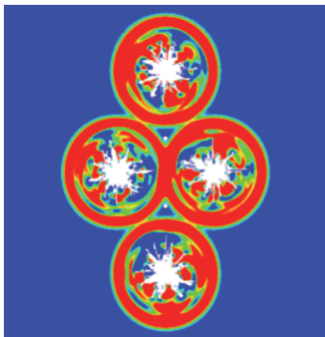

$50 \mu \mathrm{s}$

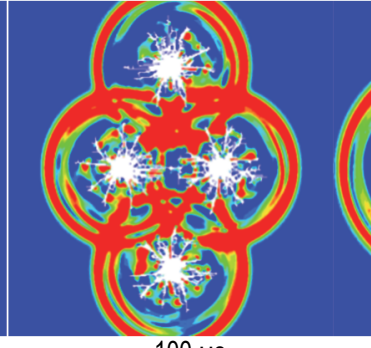

$100 \mu \mathrm{s}$

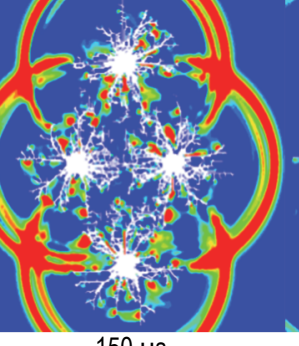

$150 \mu \mathrm{s}$

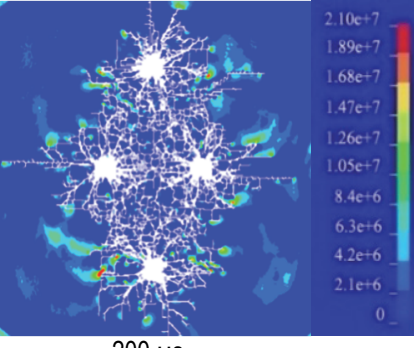

$200 \mu \mathrm{s}$

(a) Dynamic fragmentation of model I throughout the process

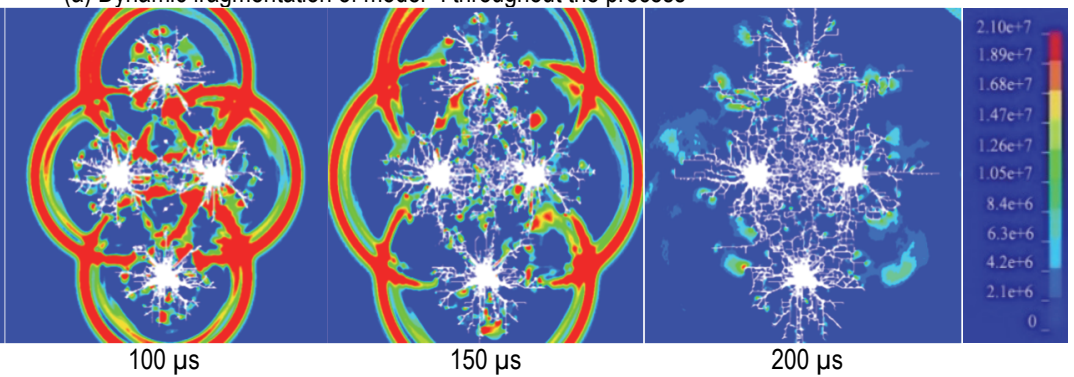

(b) Dynamic fragmentation of model II throughout the process

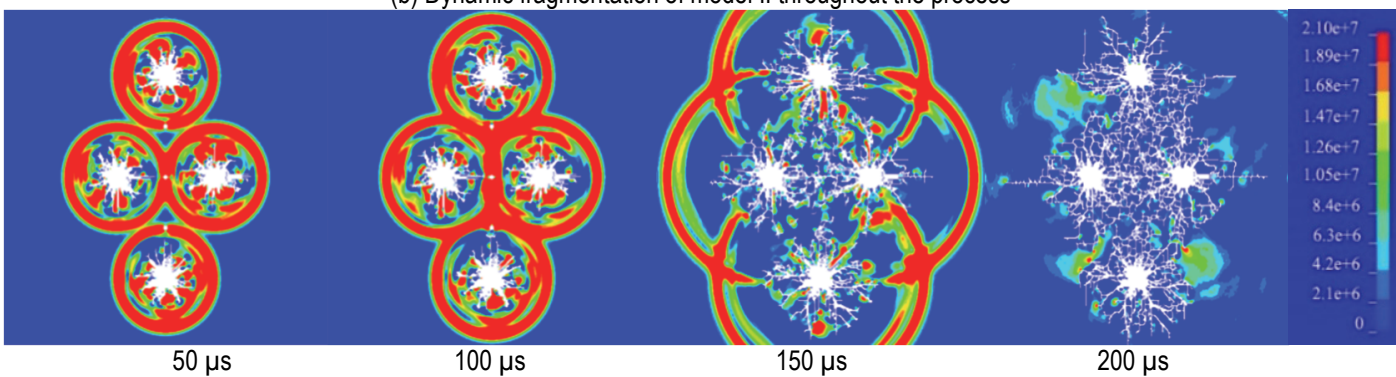

(c) Dynamic fragmentation of model III throughout the process

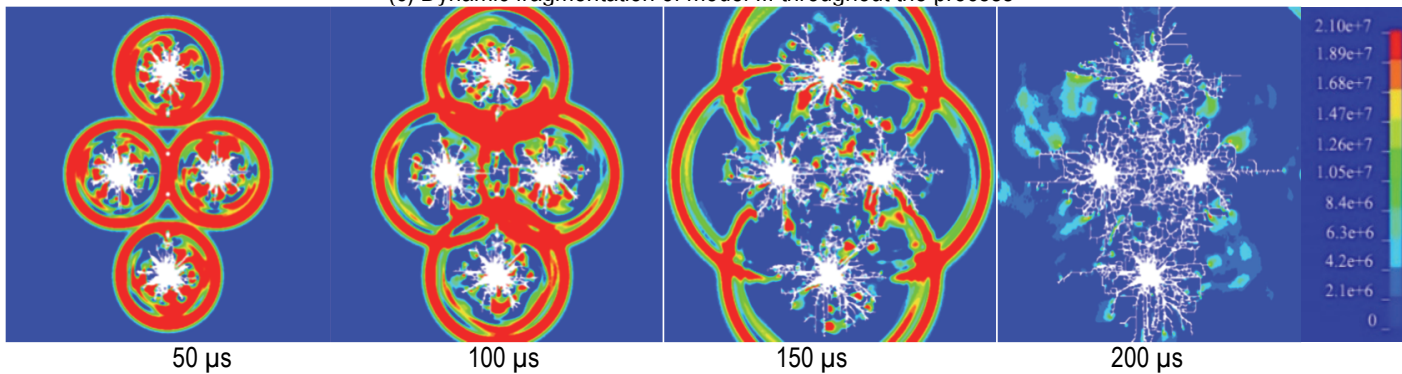

(d) Dynamic fragmentation of model IV throughout the process

Figure 2 Simulation diagram of dynamic rock breaking process of each model 
The simulation results show that the blasthole detonation is within $80 \mu \mathrm{s}$, and the explosion stress wave propagates in all directions in the form of columnar waves. The rock around the blasthole has compressive damage uniformly distributed in all directions, the stress wave does not reach the empty hole, and the empty holes effect does not appear. At about $90 \mu \mathrm{s}$, the explosion stress waves reach the center of the model and begin to stack at this time. When the stress wave reaches the central empty hole of the model I and the Model III, it can be seen from the stress cloud diagram that the stress wave generates a reflection tensile stress at the central hole of the Model I and the Model III, and a stress concentration phenomenon occurs; At about $136 \mu$ s, the Model I and the Model III center empty hole cause the tensile damage to produce the crack, the crack along the horizontal direction expands. In addition, the empty holes E and holes G in the Model III due to the proximity of the blasthole, the empty hole guiding effect is obvious. The cracks mainly develop in the direction connecting the blasthole and the empty hole. The cracks of the empty hole E and G develop vertically, and that is inconsistent with the crack development direction of the center empty hole $\mathrm{F}$, so that the cracks develop slowly when they extend to the central hole F.

This phenomenon is more evident in the Model IV. The empty hole E and the empty hole $\mathrm{H}$ in the Model IV are close to the blasthole A and the blasthole D respectively, at about $110 \mu \mathrm{s}$, because the stress wave arrives at the empty hole $\mathrm{E}$ and the empty hole $\mathrm{H}$, and produces the horizontal direction tensile stress near the empty holes, therefore, the vertical crack expansion of the empty holes appeared, and penetrated in the main at $178 \mu \mathrm{s}$. This phenomenon effectively suppresses the crack propagation on the left and right sides of the two empty holes. The stress wave of the blasthole $\mathrm{B}$ and the blasthole $\mathrm{C}$ is superimposed at the empty hole $F$ and the empty hole $G$ at about $118 \mu \mathrm{s}$, and the vertical tensile stress is produced near the hole, which causes the horizontal crack to occur in the two holes at about $149 \mu \mathrm{s}$; the maximum principal stress direction of the empty hole $\mathrm{E}$ and empty hole $\mathrm{F}$ is different under the action of the explosive stress wave, because of the tensile stress of the hole $\mathrm{E}$ is in the horizontal direction, and the tensile stress of the empty hole $F$ is in the vertical direction, the two empty holes are different in the direction of the crack orientation, so that the empty hole is connected in a large amount of rock.

Since the two empty holes in the Model II are far away from the blasthole, stress concentration occurs near the two empty holes at about $162 \mu \mathrm{s}$, and the tensile stress caused by the stress wave is pulled, and the crack propagation direction is approximately $45^{\circ}$ with the horizontal direction. The guiding effect is not obvious, resulting in a larger amount of rock that has not been exploded, which is worse than other models.

\subsection{Analysis of Numerical Simulation Results}

Since each grid volume is divided into $1 \mathrm{~cm}^{3}$ when meshing, the volume of unexploded rock mass in the explosion chamber after the end of the simulation can be roughly judged according to the number of statistically non-failed cells [19]. The volume statistics of the remaining large block rocks in the cutting cavity is shown in Tab. 4.
Table 4 Remaining maximum block volume table of rock mass

Maximum block mass of remaining rock mass $/ \mathrm{cm}^{3}$

\begin{tabular}{|l|l|l|l} 
Model I & Model II & Model III & Model IV \\
\hline
\end{tabular}

100

400

80

After comparing the dynamic rock breaking process of four models, it is found that the model simulates the final cavity Volume: Model I > Model II > Model III > Model IV.

It can be seen from the simulation results that with the increase of the number of empty holes, the guide direction of the empty holes becomes inconsistent: In the Model III, the tensile stress in the middle empty hole is in the vertical direction, the crack is mainly horizontal, but the reflection tensile stress of the remaining two empty holes is in the horizontal direction, the crack along the vertical, leading to the formation of the cutting cavity inhibition, the remaining large size rock mass began to increase. In the Model IV, because the crack propagation direction of the empty hole $\mathrm{E}$ and the empty hole $\mathrm{F}$ is inconsistent, the rock block with the final cavity opening is the largest, the quantity is large, the cutting cavity is small, and the blasting effect is unsatisfactory. In the Model II, in addition to the large size and the number of larger, the guiding effect is not obvious, and the simulation results show that there are nonpenetrating surfaces. The volume of the cutting cavity is smaller than the Model I.

The stress state of rock in the process of explosive loading is an important part of analyzing the law and characteristics of rock breaking, and the action process of explosive load to rock mass can be analyzed comprehensively by analyzing the stress characteristics of rocks at different positions. Take a unit at a distance of 200 $\mathrm{mm}$ from each blasthole to check the detonation pressure at that place. The location and unit number of each model are the same. The specific settings are shown in Fig. 3.

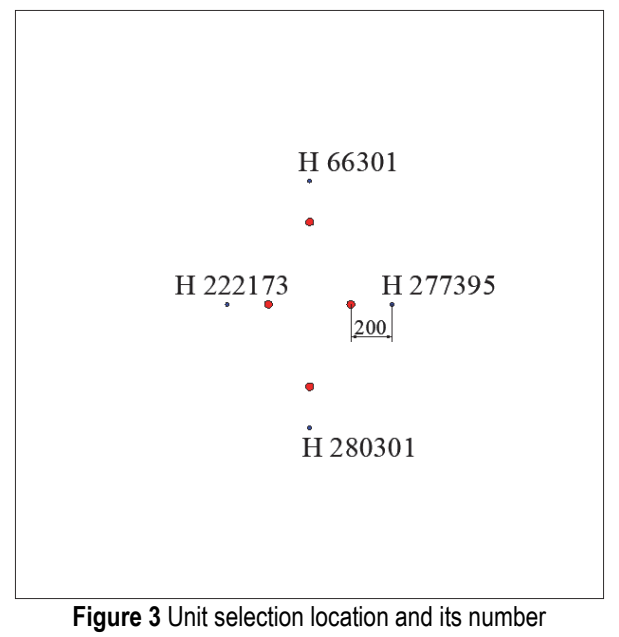

The detonation pressure of the selected unit is shown in Fig. 4.

When the stress wave reaches the empty hole, the radial wave is generated near the wall of the hole under the action of the stress wave and the air in the hole, and then the rock near the empty hole is continuously destroyed under the "gas blade action" of the air. The presence of empty holes slow the decay of stress waves in the rock, so that as the number of empty holes increases and the distance between the empty holes and the blastholes 
decreases, the peak of the detonation pressure gradually increases, which promotes the propagation of stress waves. However, due to the attenuation of the stress wave, the effect of the empty hole on the propagation of the stress wave will reach a peak and then gradually decrease.

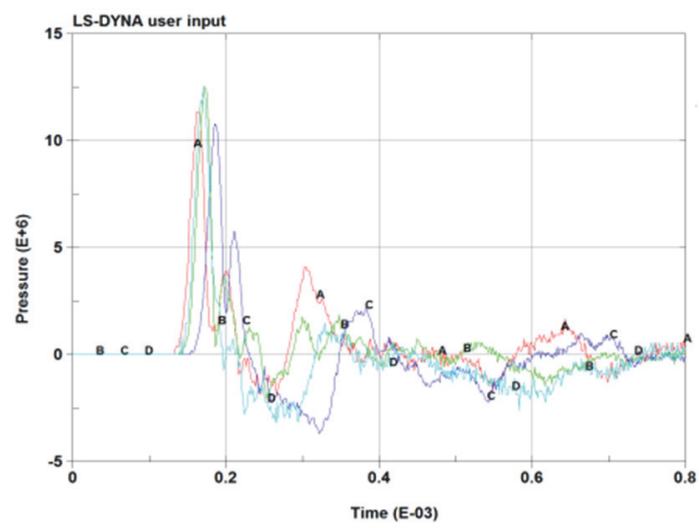

(a) Model I detonation pressure diagram

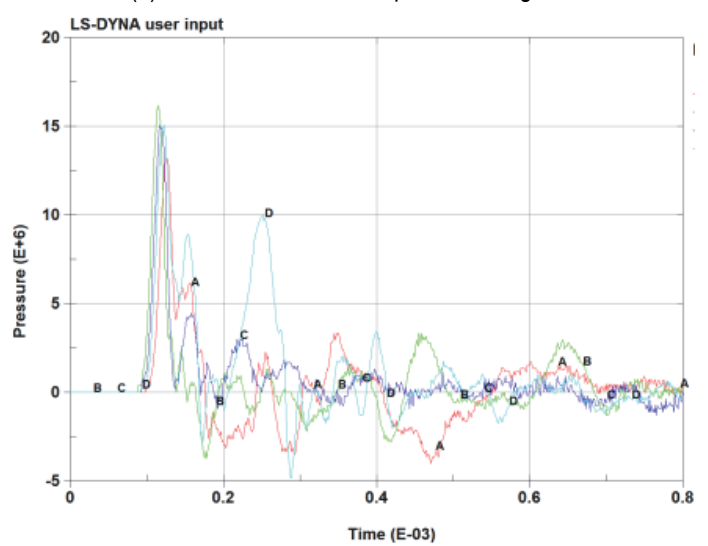

(b) Model II detonation pressure diagram

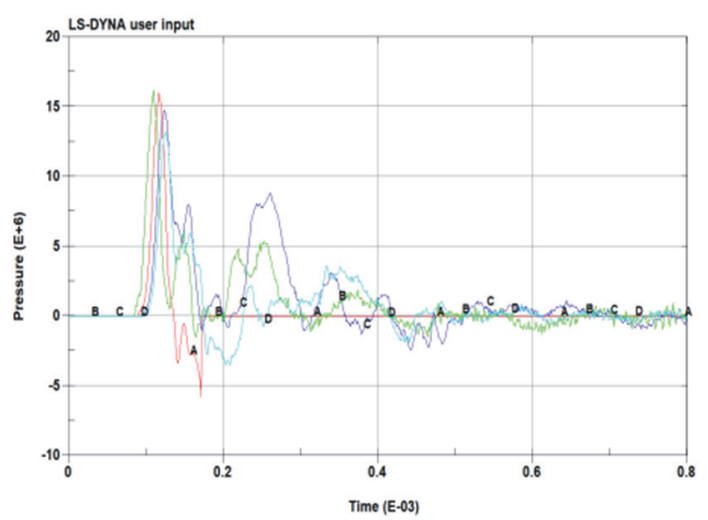

(c) Model III detonation pressure diagram

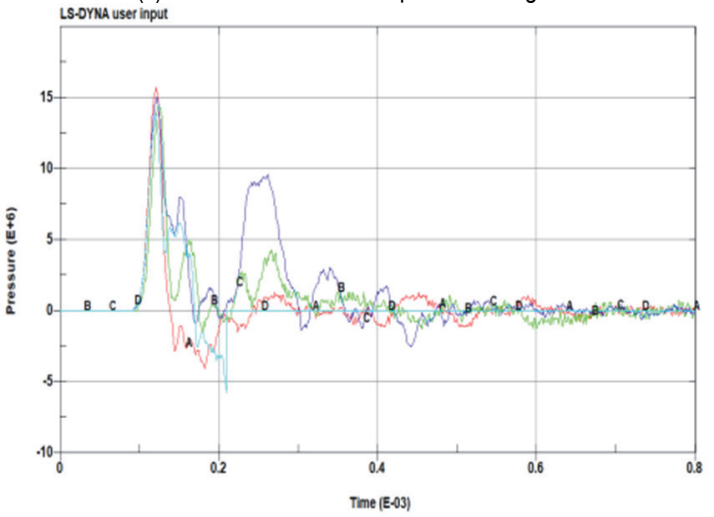

(d) Model IV detonation pressure diagram

Figure 4 Detonation pressure diagram of selected unit of each model
Combined with the simulation of the dynamic rock breaking process of each model in Fig. 2, it can be seen that as the number of holes increases and the distance between the empty holes and the blastholes decreases, the guiding effect of the empty holes on the cracks becomes less obvious, and the suppression of crack propagation in the remaining directions is gradually weakened. The crack on the outside of the blastholes becomes denser and more random as the distance between the empty hole and the blastholes increases.

\section{THEORETICAL VERIFICATION OF THE EFFECT OF EXPLOSION STRESS WAVE ON EMPTY HOLE}

The stress state near the empty hole is very different from that without it, and the stress concentration near the empty hole has a great influence on the guide direction of the empty hole. Each model bore a coupling charge, and at the same time, the detonation of the blast wave quickly decays to the stress wave, the peak attenuation law of the stress wave is shown in Eq. (3) [19, 20].

$$
\left\{\begin{array}{c}
\sigma_{r}=p_{0}\left(\frac{r}{r_{0}}\right)^{-\alpha} \\
\sigma_{\theta}=-\lambda_{\mathrm{d}} \sigma_{r}
\end{array}\right.
$$

where, $\sigma_{r}$ is an additional radial stress in the explosion of a point in the rock, $\mathrm{MPa} ; \sigma_{\theta}$ is the tangential stress of an explosion at a point in the rock, $\mathrm{MPa} ; p_{0}$ is the initial pressure applied to the hole wall after the explosive explosion, $\mathrm{MPa} ; \gamma_{0}$ is the hole radius, $\mathrm{m} ; \gamma$ is the distance from the center of the cannon Hole in the rock, $\mathrm{m} ; \alpha$ is the stress wave attenuation factor, and its relation is $2-\mu_{\mathrm{d}} /(1$ $\left.-\mu_{\mathrm{d}}\right) ; \mu_{\mathrm{d}}$ is the dynamic Poisson ratio, and the relationship to the static Poisson ratio is $\mu_{\mathrm{d}}=0.8 \mu ; \lambda_{\mathrm{d}}$ is the dynamic side stress coefficient, and its relation is $\lambda_{\mathrm{d}}=\mu_{\mathrm{d}} /\left(1-\mu_{\mathrm{d}}\right)$.

When the stress wave reaches the empty hole, the reflective tensile action at the wall of the holes will cause the stress concentration phenomenon near the empty hole. At this time, the stress peaks near the empty holes are shown by the theoretical Mechanics Eq. (4) [21-24]:

$$
\left\{\begin{array}{l}
\sigma_{r r}=\frac{1}{2}\left[\begin{array}{l}
\left(1-k^{2}\right)\left(\sigma_{\theta}-\sigma_{r}\right)+ \\
+\left(1-4 k^{2}+3 k^{2}\right)\left(\sigma_{\theta} \cos 2 \theta+\sigma_{r} \cos 2 \theta\right)
\end{array}\right] \\
\sigma_{\theta \theta}=\frac{1}{2}\left[\begin{array}{l}
\left(1+k^{2}\right)\left(\sigma_{\theta}-\sigma_{r}\right)+ \\
+\left(1+3 k^{2}\right)\left(\sigma_{\theta} \cos 2 \theta+\sigma_{r} \cos 2 \theta\right)
\end{array}\right] \\
\tau_{r \theta}=\frac{1}{2}\left[\left(1+2 k^{2}-3 k^{2}\right)\left(\sigma_{\theta} \cos 2 \theta+\sigma_{r} \cos 2 \theta\right)\right] \\
k=\frac{r_{2}}{r_{\mathrm{B}}}
\end{array}\right.
$$

where, $\sigma_{r r}$ is the radial stress under the effect of the empty holes, MPa; $\sigma_{\theta \theta}$ is the tangential stress under the void hole effect, $\mathrm{MPa} ; \tau_{r \theta}$ is the shear stress under void hole effect, $\mathrm{MPa} ; r_{2}$ is the empty hole radius, $\mathrm{m} ; \theta$ is the angle between the calculation point and the center line of the cannon Hole and the line of the empty hole center. $r_{\mathrm{B}}$ is the distance from 
the point to the center of the empty hole, $m$.

By analyzing the above two formulas, they can calculate the stress peaks near the hole wall and the hole wall, however the stress peak calculation of the other points in the cutting cavity after the stress wave superposition has problems, but the numerical simulation can get the stress state of any point.

Substituting the parameters into the formula, $r_{2}=r_{\mathrm{B}}, k$ $=1$ : $\sigma_{r r}=0 ; \tau_{\gamma \theta}=0 ; \sigma_{\theta \theta}=\sigma_{\theta}(1+2 \cos \theta)+\sigma_{r}(2 \cos \theta-1)$, when $\theta= \pm \pi$, the maximum principal stress size near an empty hole is: $\sigma_{\theta \theta \max }=3 \sigma_{\theta}+\sigma_{r}=p_{0}\left(r / r_{0}\right)^{\wedge}(-\alpha)-3 \lambda_{\mathrm{d}} \sigma_{r}$

The calculation results of the maximum principal stress at each hole wall are compared with the simulation results as shown in Tab. 5. After comparison, the calculation results are numerically different from the simulated values, but the sizes are not much different, and the variation law is consistent.

Table 5 Calculated results and simulation results of maximum principal stress at each empty hole wall (MPa)

\begin{tabular}{|c|c|c|c|c|c|}
\hline \multicolumn{2}{|c|}{ Model number } & $\mathrm{E}$ & $\mathrm{F}$ & $\mathrm{G}$ & $\mathrm{H}$ \\
\hline \multirow{2}{*}{ Model I } & Calculated values & 135 & & & \\
\hline & Simulation results & 127 & & & \\
\hline \multirow{2}{*}{ Model II } & Calculated values & 74 & 64 & & \\
\hline & Simulation results & 68 & 57 & & \\
\hline \multirow{2}{*}{ Model III } & Calculated values & 78 & 118 & 62 & \\
\hline & Simulation results & 71 & 110 & 57 & \\
\hline \multirow{2}{*}{ Model IV } & Calculated values & 91 & 100 & 97 & 72 \\
\hline & Simulation results & 79 & 89 & 86 & 66 \\
\hline
\end{tabular}

\section{CONCLUSIONS}

The finite element software is used to simulate the crack penetration process of a different number of empty holes and the break-through process of the cutting cavity, and the following conclusions are obtained by the numerical simulation and the theoretical analysis of the effect of the stress wave on the empty hole, and the conclusions are as follows:

(1) The guide direction of the empty hole is the maximum principal stress direction; the crack around the empty hole is caused by the continuous action of the stress wave; due to the stress concentration phenomenon of the empty hole, the crack mainly develops to the empty hole connection direction, and the other direction crack propagation is suppressed. The guiding action of the empty hole is more obvious, the stronger the suppression of crack propagation in other directions, the cavity volume will be reduced correspondingly. At the same time, the empty hole promoted the propagation of the explosion stress wave, and this promotion is gradually weakened due to the attenuation of the stress wave.

(2) When the multi-empty hole is arranged, the inconsistent orientation direction of the adjacent empty holes will lead to less crack through the empty holes or even wear, so that the blasting effect is not ideal or even the blasting failure. In the actual blasting construction, the arrangement position of the empty holes and the density of the empty holes should be considered, and whether the guiding direction of the adjacent empty holes is conducive to the formation of the cavity.

(3) The theoretical calculation and numerical simulation results of the effect of the explosion stress wave on the cavity show the following: the existence of the empty hole changes the stress distribution around the empty hole and produces the stress concentration phenomenon. By comparing the stress simulation results and the calculation results around the holes, the closer the empty holes are to the blasthole, the larger the maximum principal stress. It shows that in the process of stress wave propagation, as the stress wave propagates outward, the attenuation trend appears. The maximum principal stress of the empty hole is similar to the symmetrical arrangement, the simulation result is similar to the calculated result, and the change law is consistent.

\section{Acknowledgments}

This study was supported by the National Natural Science Foundation of China (51874189, 51709161, 41772299), the financial supports are gratefully acknowledged.

\section{REFERENCES}

[1] Li, Q.Y., Xu, M., Fan, Z.P. et al. (2011). Simulation of Rock Failure Process in Cutting by Parallel Hole and Analysis on Empty Hole Effect, BLASTING, 28(04), 23-26.

[2] Zhang, Q., Yang, Y. Q., Yuan, Y. F. et al. (2001). Study on the factors affecting parallel hole cut blasting. Rock and Soil Mechanics, (02), 144-147.

[3] Lin, D. N. \& Chen, S. R. (2005). Experimental and theoretical study of parallel hole cut blasting with cavity. Rock and Soil Mechanics, (03), 479-483.

[4] Ren, X., Fu, J. G., \& Luo, J. (2015). Parallel Cut Blasting Hollow Hole Stress Concentration Effect Numerical Simulation. Coal Technology, 34(01), 195-197.

[5] Zhu, Z. M., Wang, Y., Zhou, Z. T. et al. (2008). A new fracture criterion for brittle materials under compression. Journal of Sichuan University (Engineering Science Edition), (05), 13-21.

[6] Yang, R. S., Chen, C., Wang, X. et al. (2017). Experimental investigation on the influence of different diameter empty holes on the crack growth behavior of blasting. Journal of china coal socie, 42(10), 2498-2503.

[7] Li, M., Zhu, Z. M., Liu, R. F. et al. (2018). Study of the effect of empty holes on propagating cracks under blasting loads. International Journal of Rock Mechanics \& Mining Sciences, 103, 186-194. https://doi.org/10.1016/j.jirmms.2018.01.043

[8] Wang, Y. B., Yang, R. S., Zhao, G. F. et al. (2017). Influence of empty hole on crack running in PMMA plate under dynamic loading. Polymer Testing, 58, 70-85. https://doi.org/10.1016/j.polymertesting.2016.11.020 
[9] Yan, Y. F. (2017). Dynamic analysis and Optimization Study of deep hole cutting blasting for roadway drivage. Wu Han: Wuhan Institute of Technology.

[10] Long, Z., Lin, D. N., Liu, Y. S. et al. (2012). Study on the blasting experiment of parallel cuts by applying angle column shaped and big empty holes in the small section roadways located in hard rock. Mineral Engineering Research, 27(03), 1-5.

[11] Zhang, X. T., Ji, Y. G., Zhou, H. M. et al. (2016). Comparative Analysis on Blasting Effect of Different Cutting Blasting for the Sandstone Tunnel Drivage in Iron Mine. Journal of the Balkan Tribological Association, 22(IA), 1029-1014

[12] Zhang, X. T. \& Chen, S. H. (2000). Study on shape prediction of rock burst in jointed fissure. Coal Mine Blasting, (03), 9-12.

[13] Dai, J., Li, C. J., Chen, Z. H. et al. (2017). Simulation of Crack Growth in Adjacent Blasting Holes of Smooth Blasting. Science Technology and Engineering, 17(18), 193197.

[14] Zhang, X. T. \& Chen, S. H. (2002). Study on Blast fragmentation for Jointed and Fractured Rock mass Considering Collision. Chinese Journal of Rock Mechanics and Engineering, (08), 1141-1146.

[15] Zhang, Q., Wang, X. L., Yang, Y. Q. et al. (2001). A Model for Analysis of the Blasting Effect of Parallel Cut. Engineering Blasting, (01), 1-6.

[16] Ji, Y. G. (2018). Numerical simulation study on rock breaking mechanism by blasting with three blasthole in single row under different confining pressure conditions. Qing Dao: Shandong University of Science and Technology.

[17] He, C. \& Wang H. L. (2017). Research on Blasting Effect Based on Four Different Cutting Types. Highway, 62(02), 250-254.

[18] Yang, Y. P. \& Hu, D. J. (2015). Testing on Medium Length Hole Blasting Technique of Compound Barrel Straight Cutting in Tunnel Excavating. Gold Science and Technology, 23(06), 64-69.

[19] Pan, X. F. \& Mao, Y. F. (2014). The numerical simulation of shaft excavation blasting cavity expansion process based on ANSYS/LS-DYNA. Coal Mine Blasting, (04), 19-24.

[20] Shan, R. L., Huang, B. L., Wei, Z. T. et al. (2012). Model Test of Quasi-parallel Cut Blasting In Rock Drivage. Chinese Journal of Rock Mechanics and Engineering, 31(02), 256264.

[21] Zhang, Q., Zhang, Y. M., \& Luo, K. L. (1997). Parameter Calculation for Multi-step and Multi-stage Blasting with Vertical Borehole Cutting, Rock and Soil Mechanics, (02), 51-56.

[22] Sun, Z., Xie, S. Z., Zhang, X. T. et al. (2019). Vibration reduction effect of damping holes in blasting excavation of tunnels with small spacing. Journal of Shandong University of Science and Technology (Natural Science), 38(1), 25$31+39$.

[23] Zheng, Z. T. (2017). 3D Mosel Test of ultra-deep-hole column charge blasting in high geostress rock mass. He Fei: Anhui University of Science \& Technology.

[24] Guan, S.H. (2015). Experimental Research on Blasting Crack Propagation and controlled under Eccentric Decouple Charge Structure. Mian Yang: Southwest University of Science and Technology.

\section{Contact information:}

Xiantang ZHANG, PhD, Prof.

(Corresponding author)

Shandong Provincial Key Laboratory of Civil Engineering Disaster Prevention and Mitigation,

College of Civil Engineering and Architecture,

Shandong University of Science and Technology,

Qingdao 266590, China

E-mail: zzxhtm@sdust.edu.cn

Juan LI, MSC

Shandong Provincial Key Laboratory of Civil Engineering Disaster Prevention and Mitigation,

College of Civil Engineering and Architecture,

Shandong University of Science and Technology,

Qingdao 266590, China

Dan LI, PhD

College of Earth Science and Engineering,

Shandong University of Science and Technology,

Qingdao 266590, China

\section{Shizhen XIE, MSc}

Linyi Urban Construction Investment Group Co. Ltd

Linyi 276100, China

Hongmin ZHOU, PhD, Associate Professor

Shandong Provincial Key Laboratory of Civil Engineering Disaster Prevention and Mitigation,

College of Civil Engineering and Architecture,

Shandong University of Science and Technology,

Qingdao 266590, China

Tingchun LI, PhD, Prof.

Shandong Provincial Key Laboratory of Civil Engineering Disaster Prevention and Mitigation,

College of Civil Engineering and Architecture

Shandong University of Science and Technology,

Qingdao 266590, China 